\title{
Meta
}

Journal des traducteurs

Translators' Journal

\section{Mounin, Georges (1994) : Les belles infidèles, Paris, Presses Universitaires de Lille, 109 p.}

\section{Georges L. Bastin}

Volume 40, numéro 4, décembre 1995

URI : https://id.erudit.org/iderudit/001991ar

DOI : https://doi.org/10.7202/001991ar

Aller au sommaire du numéro

Éditeur(s)

Les Presses de l'Université de Montréal

ISSN

0026-0452 (imprimé)

1492-1421 (numérique)

Découvrir la revue

Citer ce compte rendu

Bastin, G. L. (1995). Compte rendu de [Mounin, Georges (1994) : Les belles infidèles, Paris, Presses Universitaires de Lille, 109 p.] Meta, 40(4), 654-655.

https://doi.org/10.7202/001991ar

Ce document est protégé par la loi sur le droit d'auteur. L'utilisation des services d'Érudit (y compris la reproduction) est assujettie à sa politique d'utilisation que vous pouvez consulter en ligne.

https://apropos.erudit.org/fr/usagers/politique-dutilisation/
Cet article est diffusé et préservé par Érudit.

Érudit est un consortium interuniversitaire sans but lucratif composé de l'Université de Montréal, l'Université Laval et l'Université du Québec à Montréal. Il a pour mission la promotion et la valorisation de la recherche. https://www.erudit.org/fr/ 


\section{Comptes rendus}

MOUNIN, Georges (1994) : Les helles infideles, Paris, Presses Universitaires de Lille, $109 \mathrm{p}$.

Beaucoup d'eau a coulé sous le pont de la traductologie depuis 1955 ; quarante ans après.... le texte n'a pas vieilli, ni dans sa forme, ni dans son contenu. Quoi qu'il en soit, nombre de chercheurs en traductologie qui publient dans les pages de Meta ont aujourd hui, à peu de choses près, l'âge de cet ouvrage. Il est bon, voire indispensable, qu'ils le lisent, le relisent. Tous ceux d'entre nous qui avons lu Les helles infideles dans les bibliothèques avons maintenant la chance de le posséder, précisément pour y puiser avec davantage de commodité les enseignements qu'il renferme. Que les Presses Universitaires de Lille en soient remerciées.

Les helles infideles n'est pas une analyse scientifique profonde des problèmes de traduction. Cet essai ne procède pas non plus d'une motivation didactique. Il n'a pas la prétention de la thèse doctorale ni du manuel pédagogique. Comment dès lors cet ouvrage est-il devenu un classique? Immédiatement précédé par des textes, désormais classiques eux aussi, comme La tâche du traducteur (1923) de Walter Benjamin, Miseria y esplendor de la traducción (1937) de José Ortega y Gasset et Droits et devoirs du traducteur (1946) de Valery Larbaud, Les helles infidèles fait figure de précurseur dans la description historique de la manière de traduire. Il a, sur ces autres textes, l'avantage de la clarté et de la simplicité sans pour autant moins de rigueur.

$S$ 'il est vrai que l'ouvrage $n$ 'est pas une thèse académique, ni par le détail ni par la taille, il n'en constitue pas moins un engagement, une profession de foi et un vou... richement illustrés et savamment exposés. On a plaisir à lire le témoignage et surtout la conviction de ce traducteur et lecteur de traductions. Conviction de la possibilité de la traduction étayée par la réfutation de presque tous les arguments contraires avancés au cours des temps. On reste cependant étonné de la force d'une telle conviction, lorsque l'on sait que huit ans plus tard, dans sa thèse sur ce qu'il conviendrait d'appeler les problèmes «linguistiques» (plutôt que «théoriques») de la traduction, Georges Mounin nuance cette possibilité de la traduction, avec une vue nettement moins optimiste, puisqu'elle devient «une opération relative dans son succès, variable dans les niveaux de la communication qu'elle atteint".

Comme l'ont répété tous les commentateurs, l'ouvrage est avant tout une «défense et illustration de la traduction». Illustrer, bien. et Mounin y réussit admirablement. Mais pourquoi avoir toujours à se défendre ? Pourquoi surtout se défendre de préjugés, même s'ils sont tenaces? Pourquoi encore s'excuser d'avoir écrit un Paradoxe sur la traduction. comme l'affirme l'auteur dans sa conclusion? Georges Mounin avait certes, il y a quarante ans, de bonnes raisons d'agir et d'écrire ainsi. Joachim du Bellay, son bouc émissaire, aura eu le mérite de stimuler une réflexion exemplaire. En 1995, on aurait tort de croire la situation différente. Bon nombre de chercheurs d'aujourd'hui continuent de 
régler des comptes. Entre eux, cela peut être enrichissant pour le lecteur. Mais avec des préjugés?

On ne saurait cependant regretter les petits conseils que nous donne Mounin. comme par exemple "C'est un tic de traducteur que ces petites notes au bas des pages, où l'on avertit le lecteur que tel ou tel mot, qu'on vient de traduire, et qu'on cite, est pourtant proprement intraduisible» (p. 28) ou celui de la leçon de syntaxe entre Monsieur Jourdain et son maître de philosophie, "leçon qu'il faut conseiller à tous les traducteurs d'apprendre par cœur et de méditer" (p. 83). De même, les mises en garde contre certaines tendances modemes, comme le "pédantisme radiophonique grandissant" (p. 79): et les urèglements de compte» avec la traduction de Robinson Crusoé dont "le texte intégral $[. . . \mid$ surprendrait plus d'un lecteur français» (pp. 65-66) et avec les «tenants de l'irréductibilité des images» (p. 75). Ces commentaires, faits en boutades, qui étoffent l'ouvrage en font un régal.

On ne peut indéfiniment rendre compte de la réédition d'un classique sans courir le risque de lasser, par avance, le futur lecteur ou le ure-lecteur». Ajoutons, pour conclure. que cette nouvelle édition s'accompagne avantageusement d'une Préface opportune et riche, signée Michel Ballard et Lieven D'hulst, ainsi que d'une Bibliographie des travaux de Georges Mounin sur la traduction, présentée par M. Ballard et largement inspirée de celle de Conrad Bureau. Bref, un nouveau succès de la collection Étude de la traduction des Presses Universitaires de Lille. 